\title{
Movimentos sociais do campo e a afirmação do direito à educação: pautando o debate sobre as escolas multisseriadas na Amazônia paraense
}

Salomão Mufarrej Hage

\section{Resumo}

Analisa a realidade das escolas multisseriadas localizadas na Amazônia paraense, inserindo as particularidades dessas escolas nos desafios mais abrangentes que enfrentam os movimentos sociais populares do campo para afirmar o direito à educação e à vida com dignidade das populações. Socializa os resultados de uma pesquisa que envolveu estudo bibliográfico e documental e entrevistas com estudantes, professores, gestores, pais e lideranças comunitárias, com o objetivo de motivar uma discussão conseqüente com o poder público e a sociedade civil que resulte num compromisso efetivo, por parte desses órgãos e instituições, de incluir em sua agenda política o enfrentamento do abandono e da precarização que caracteriza o processo de escolarização no ensino fundamental ofertado nas escolas multisseriadas.

Palavras-chave: educação do campo; movimentos sociais; escolas multisseriadas; políticas educacionais.

\section{Abstract}

Social movements in the countryside and the right to education: regulating the debate on multi-grade schools in the Pará Amazon

This article analyzes the reality of multi-grade schools in the Pará Amazon. It inserts the particularities of these schools within the broader challenges that popular social movements in the countryside face in asserting the right to education and a dignified life for rural people. It shares the results of a research project that employed secondary sources and documents, as well as interviews with students, teachers, administrators, parents and community leaders. The objective is to motivate an important discussion with the State and the civil society, which results in an effective commitment on the part of these organizations and institutions to include in their political agenda an offensive against the abandonment and precarious conditions that characterize the educational process at the elementary level in multi-grade schools.

Keywords: countryside education; social movements; multi-grade schools; educational policies. 


\section{Introduzindo a problemática e apresentando os horizontes da investigação}

Os movimentos sociais populares do campo, nas últimas décadas, têm participado ativamente das disputas que envolvem a conquista da terra, o fortalecimento da agricultura familiar e a garantia do direito à vida com dignidade, constituindo-se sujeitos coletivos de direito, entre os quais se encontra o direito à educação.

Nessa caminhada de mobilização e protagonismo, a articulação nacional Por uma Educação do Campo tem assumido um papel destacado para que não sejam reeditadas as tradicionais políticas de manutenção precária das escolas rurais de cunho assistencialista, compensatório e compassivo, que reforçam o atraso e o abandono secular da educação dos povos que vivem da agricultura, do extrativismo e do trabalho do campo (II CNEC, 2004, p. 3).

Essa articulação, considerada atualmente uma das expressões de mobilização por uma educação do campo no Brasil, reúne órgãos do poder público, ONGs e movimentos sociais do campo, entre os quais se destacam o Movimento dos Trabalhadores Rurais Sem Terra (MST), a Confederação Nacional dos Trabalhadores na Agricultura (Contag), a Conferência Nacional dos Bispos do Brasil (CNBB), a Organização das Nações Unidas para a Educação, a Ciência e a Cultura (Unesco), o Fundo das Nações Unidas para a Infância (Unicef), a Universidade de Brasília (UnB), o Programa Nacional de Educação na Reforma Agrária (Pronera), o Instituto Nacional de Colonização e Reforma Agrária (Incra), o Núcleo de Estudos Agrários e Desenvolvimento Rural (Nead), o Ministério do Desenvolvimento Agrário (MDA) e a Coordenação Geral de Educação do Campo, do Ministério da Educação.

A primeira e a segunda Conferência Nacional de Educação do Campo, ocorridas respectivamente em 1998 e 2004, em Luziânia, Goiás, se constituíram marcos históricos dessa articulação nacional nesse processo de afirmar o direito das populações do campo à educação, ao reivindicar que a educação do campo seja assumida como política pública de maneira mais explícita; que os órgãos públicos responsáveis pela educação em nosso País se façam mais presentes, reconhecendo a dívida social, cultural e educativa que têm para com os diversos sujeitos que vivem no campo e na floresta; e que seja reconhecida a especificidade desses povos e de suas formas de viver e de ser, de formarse, socializar-se, aprender, de produzir e relacionar-se com o conhecimento, com as ciências e as tecnologias, com os valores e com a cultura. (II CNEC, 2004, p. 4).

Uma conquista recente desse processo de mobilização no âmbito das políticas públicas educacionais - envolvendo a participação dos Conselhos Estaduais e Municipais de Educação, da SEF/MEC, do Consed, da Undime, de universidades e instituições de pesquisa, do Conselho Nacional de Desenvolvimento Rural Sustentável e de ONGs - foi a aprovação das "Diretrizes Operacionais para a Educação Básica nas Escolas do Campo", que se constituem um conjunto de princípios e procedimentos que visam adequar o projeto institucional das escolas do campo às políticas curriculares nacionais vigentes, intencionando legitimar a identidade própria dessas escolas, que deve ser definida ancorando-se na temporalidade e saberes próprios dos povos do campo, em sua memória coletiva, na rede de ciência e tecnologia disponível na sociedade e nos movimentos sociais, contemplando o campo em sua diversidade social, cultural, política, econômica, de gênero, geração e etnia (Resolução 1/2002 do CNE/ CEB).

Outro indicativo desse processo organizativo em curso tem sido a pressão sobre as várias instâncias governamentais para que renovem os processos de gestão da educação, ação que tem resultado num esforço de determinadas Secretarias de Educação para se tornarem mais sensíveis à inclusão da educação do campo em sua agenda política, criando espaços e situações em que as especificidades do campo sejam reconhecidas e valorizadas. Nessa perspectiva, o próprio MEC tem respondido a essa mobilização, com a criação, em 2004, da Secretaria de Educação Continuada, Alfabetização e Diversidade (Secad), onde se insere a Coordenação Geral da Educação do Campo, que assumiu como meta pôr em prática uma política de educação que respeite a diversidade cultural e as diferentes experiências de educação em desenvolvimento, em todas as regiões do País, como forma de ampliar a oferta de educação de jovens e 
adultos e da educação básica nas escolas do campo (Secad, 2005).

Nos documentos que expressam as intencionalidades oficiais com relação à definição e implementação de políticas educacionais, têm-se reconhecida a reivindicação dos movimentos sociais de conceber e valorizar o campo em sua diversidade, "que engloba os espaços da floresta, da pecuária, das minas, da agricultura, dos pescadores, dos caiçaras, dos ribeirinhos e dos extrativistas como espaço de inclusão social, a partir de uma nova visão de desenvolvimento" (Secad, 2005).

Não obstante a identificação dos indicadores de vitalidade desencadeados através dos processos de mobilização sinalizados, a situação de penúria vivenciada pelos sujeitos que estudam nas escolas existentes no meio rural nos remete a focalizar e compreender com mais radicalidade as contradições que se materializam entre os discursos inovadores e entusiastas e a realidade existencial que revela situações de abandono e descompromisso para com a qualidade da educação que é ofertada aos sujeitos do campo em nosso país e na Amazônia.

O descaso com que tem sido tratada a base do processo de escolarização das populações do campo por entidades governamentais e não-governamentais e pelos movimentos sociais do campo se constitui um exemplo significativo das contradições entre discurso e prática referidos anteriormente. A pesquisa que referencia a realização deste artigo revelou que, para além dos indicadores de vitalidade mencionados, os sujeitos do campo ainda são obrigados a se submeterem a um processo de escolarização nas séries iniciais do ensino fundamental que se consubstancia como uma precarização do modelo seriado urbano de ensino, materializado na experiência das escolas multisseriadas, que, em grande medida, se constituem a única alternativa para que esses sujeitos tenham acesso à escolarização nas comunidades em que vivem.

As implicações dessa realidade podem ser identificadas nos altos índices de analfabetismo e exclusão escolar no campo, na existência de prédios escolares depauperados, na definição de currículos deslocados da realidade, na presença de muitos docentes sem a qualificação necessária e na ausência de um financiamento apropriado que oportunize o estudo com dignidade aos sujeitos do campo, situações essas que, em geral, são muito pouco investigadas (e sobretudo ocultadas) em face do descumprimento da legislação atual, que já aponta marcos operacionais da qualidade que deveriam ser alcançados na educação básica nas escolas do campo.

Reconhecendo essa situação estapafúrdia, este artigo foi elaborado com a perspectiva de pautar a discussão sobre a problemática que envolve as escolas multisseriadas nesse contexto mais amplo, de mobilização pela garantia do direito à educação que se efetiva a partir da articulação nacional Por uma Educação do Campo. Ele busca, como intencionalidade, motivar uma discussão conseqüente com os órgãos do poder público, com as organizações não-governamentais e, em especial, com os movimentos sociais do campo, que resulte num compromisso mais efetivo, por parte desses órgãos, instituições e entidades, de incluir em sua agenda política o desafio de enfrentar o abandono e a precarização que caracterizam o processo de escolarização dos sujeitos do campo nas séries iniciais do ensino fundamental, ofertado, predominantemente pelo poder público, nas escolas multisseriadas.

Para dar consistência à discussão, estamos disponibilizando os resultados de uma pesquisa desenvolvida no biênio 20022004, que obteve financiamento do $\mathrm{CNPq}$ mediante a chamada de fomento à pesquisa Programa Norte de Pesquisa e Pós-Graduação (PNOPG) (01/2001). A pesquisa envolveu investigação bibliográfica, documental e de campo na construção de um Banco de Dados que explicita com detalhamento e sistematicidade a realidade dramática que enfrentam educadores e educandos no cotidiano das atividades educativas vivenciadas nas escolas multisseriadas, situação em que se encontram reunidos estudantes de várias séries na mesma sala de aula, com apenas uma professora.

No artigo que ora apresentamos, socializamos os aspectos mais significativos do banco de dados mencionado, que, em sua íntegra, disponibiliza estatísticas levantadas junto aos órgãos oficiais (MEC, Inep, Saeb e Seduc/PA) relativas às escolas multisseriadas em cada um dos municípios do Estado do Pará, tomando como referência o ano de 2002, e apresenta informações que revelam particularidades do processo de ensino-aprendizagem realizado 
nessas escolas, identificadas durante a realização de uma pesquisa qualitativa que envolveu estudantes, professores, pais, mães, membros das comunidades locais e gestores das secretarias municipais de educação envolvidos com as escolas multisseriadas de seis municípios do Estado do Pará (Breves, Santarém, Cametá, Moju, Marabá e Barcarena), selecionados por pertencerem às diferentes Mesorregiões do Estado e possuírem o maior número de escolas multisseriadas em sua rede de ensino.

\section{Retratos da realidade das escolas multisseriadas na Amazônia paraense}

A realidade vivenciada pelos sujeitos nas escolas existentes no campo denuncia grandes desafios a serem enfrentados para que sejam cumpridos os marcos operacionais anunciados nas legislações educacionais que definem os parâmetros de qualidade do ensino público conquistados com as lutas dos movimentos sociais populares do campo.

Dados oficiais do Inep relativos ao Censo Escolar de 2002 mostram que, no meio rural brasileiro:

a) $28 \%$ dos jovens acima de 15 anos ainda são analfabetos;

b) 3,4 anos é a média de anos de estudo nessa mesma faixa etária;

c) a distorção idade-série atinge $65 \%$ dos estudantes matriculados; $\mathrm{e}$

d) somente $25 \%$ das crianças de 4 a 6 anos são atendidas.

Apesar de concentrar mais da metade das escolas brasileiras, 97 mil das 169 mil existentes, a metade das escolas do campo ainda é de uma sala e $64 \%$ são multisseriadas. Em relação aos professores, boa parte dos que ensinam no campo tem formação inadequada, e apenas $9 \%$ completaram o ensino superior.

No caso da Amazônia, locus ampliado da pesquisa realizada, a situação no campo é preocupante, pois $29,9 \%$ da população adulta são analfabetas; 3,3 anos é a média de anos de escolarização dessa população; e $71,7 \%$ das escolas que oferecem o ensino fundamental nas séries iniciais são exclusivamente multisseriadas, atendendo $46,6 \%$ dos estudantes em condições precárias e com pouco aproveitamento na aprendizagem.

No Pará, Estado que constitui o locus específico onde o estudo se desenvolveu, os dados apresentados no relatório de pesquisa ao CNPq revelaram um quadro alarmante em que as escolas multisseriadas constituem a modalidade predominante de oferta do primeiro segmento do ensino fundamental no campo, atendendo $97,45 \%$ da matrícula nessa etapa escolar. Nessas escolas, a taxa de distorção idadesérie é de $81,2 \%$, chegando a $90,51 \%$ das crianças matriculadas na $4^{\mathrm{a}}$ série, e a taxa de reprovação equivale a $25,64 \%$, atingindo um índice de $36,27 \%$ na $1^{\text {a }}$ série (Geperuaz, 2004).

Dados do Censo Escolar de 2003 indicam o Estado do Pará com o segundo maior número de escolas multisseriadas do País, 8.675 escolas, perdendo somente para a Bahia, que tem 14.705 escolas; o mesmo se repete em relação às turmas multisseriadas, que totalizam 11.231 turmas e perde para a Bahia, que tem 21.451 (Inep, 2003). Ante essa realidade, a única política pública direcionada às escolas multisseriadas é o "Projeto Escola Ativa", que atende um percentual de 9,4\% das escolas multisseriadas do Pará.

Para além dos indicadores quantitativos apresentados, a precarização das escolas multisseriadas se faz notar por um conjunto de particularidades que comprometem o processo de ensino-aprendizagem, as quais foram identificadas durante a realização da pesquisa e serão explicitadas a seguir, com a utilização de depoimentos dos próprios sujeitos do campo envolvidos com essa realidade.

\section{Visão dos sujeitos do campo sobre a existência da escola multisseriada}

Atentar para a visão dos sujeitos do campo sobre as escolas multisseriadas é importante, para que possamos conhecer suas expectativas e interesses com relação à escola que lhes tem sido oferecida e incorporar os aspectos significativos dessa representação nas políticas educacionais a serem direcionadas ao meio rural.

A pesquisa identificou aspectos positivos e negativos, no depoimento dos sujeitos entrevistados, com relação a essa questão: 
- A escola multisseriada é boa por uma parte e por outra não. É boa porque pelo menos as crianças estão aprendendo. Todo dia a minha filha pode ir para a escola. Mas, eu acho que essa escola está precisando de ajuda, precisando de apoio. $\mathrm{O}$ fato negativo que eu vejo é que não há cada um na sua série. Cada um na sua sala seria melhor. Eles estudam todos juntos, eu acho que isso não é certo, mas a precisão está obrigando. (Mãe e participante da comunidade R. F. N.)

- Deveria ter uma escola onde tivesse séries separadas e uma professora para cada série. Não é muito boa uma escola assim, com várias séries juntas, porque o aluno tem muita precisão de aprender e desse jeito é difícil. (Mãe O. F. A.)

Entre os aspectos positivos, identificamos que as escolas multisseriadas oportunizam o acesso à escolarização na própria comunidade, evitando que os estudantes, em sua maioria crianças e adolescentes, enfrentem dificuldades de deslocamento envolvendo longas distâncias, tranqüilizando os pais nesse aspecto. A escola multisseriada também oportuniza o apoio mútuo e a aprendizagem compartilhada, a partir da convivência mais próxima estabelecida entre estudantes de várias séries e idades na mesma sala de aula, o que em determinados aspectos é considerado salutar. Para além das questões mencionadas, a existência da escola no próprio lugar em que os sujeitos vivem (no campo) tem sido reivindicada pelos movimentos sociais do campo, com a convicção de que o povo tem direito a uma educação pensada desde o seu lugar e com a sua participação, vinculada à sua cultura e às suas necessidades humanas e sociais. (Caldart, 2000).

Por outro lado, há posicionamentos que expressam insatisfação com relação à existência das escolas multisseriadas, considerando-as um "problema", por causar prejuízos ao processo de aprendizagem. Em muitos casos, os sujeitos se referem a essas escolas como "um mal necessário" e estabelecem muitas comparações entre elas e as turmas seriadas, ao abordarem o ensino-aprendizagem que ofertam, manifestando a expectativa de que as escolas multisseriadas se transformem em seriadas, como alternativa para que o sucesso na aprendizagem se efetive.

\section{Condições existenciais das escolás multisseriadas}

Os sujeitos entrevistados entendem ser as condições existenciais das escolas um dos fatores cruciais que compromete a positividade do processo ensino-aprendizagem no meio rural e, em especial, nas escolas multisseriadas, que têm sido marcadas pelo abandono e precarização, conforme podemos identificar nos seguintes depoimentos:

- A situação é muito séria. O lugar é muito pequeno, não é apropriado, ele é da comunidade. Se chover, molha. É arriscado para a própria criança pegar uma doença, porque ela vem direto para o chão e aqui passa bicho, rato, lagarto e cachorro. (Prof. J. M.)

- Nós trabalhamos com até 3 ou 4 crianças numa carteira. Isso complica o nosso trabalho, porque a gente está explicando para um, o outro já está "professora, meu colega está sacudindo a cadeira e não deixa eu copiar direito". Como é que vamos resolver isso, três crianças sentadas numa carteira? A questão da lousa melhorou, porque a gente conseguiu outras. Mas, antigamente era só uma lousa para três, quatro séries, a gente dividia um pedacinho para cada uma. (Prof ${ }^{\mathrm{a}}$ K. A. D.)

- Eu venho de casco para a escola e às vezes eu tenho que vir contra a maré e fico muito cansada. Às vezes tem muita maresia e, quando chove muito, eu não venho para a escola. (Aluna R. C. S., 13 anos, $4^{\mathrm{a}}$ série)

- No momento não tem merenda. Quando tem, a diferença é muito grande na sala de aula e não falta nenhum aluno. No interior, o dia-a-dia é muito trabalhoso, há criança que sai de sua casa e não toma nem café e vem pensando chegar na escola e merendar um pouquinho. (Prof ${ }^{\mathrm{a}}$ K. A. D.)

Os depoimentos revelam que a precariedade da estrutura física das escolas, as dificuldades dos professores e estudantes 
em relação ao transporte e às longas distâncias percorridas e a oferta irregular da merenda são alguns dos fatores que provocam a infreqüência e a evasão e prejudicam a obtenção de bons resultados no processo ensino-aprendizagem, sendo, portanto, fatores que contribuem para o fracasso escolar que se evidencia nas escolas do campo e particularmente na multissérie.

De fato, estudar nessas condições desfavoráveis não estimula os professores e os estudantes a permanecer na escola ou sentir orgulho de estudar em sua própria comunidade, fortalecendo ainda mais o estigma da escolarização empobrecida que tem sido ofertada no meio rural e incentivando as populações do campo a buscar alternativas de estudar na cidade como solução dos problemas enfrentados.

Buscando enfrentar essa dificuldade, as Diretrizes Operacionais para a Educação Básica nas Escolas do Campo indica o cumprimento da atual LDB, que determina a diferenciação do custo-aluno com vista ao financiamento das escolas do campo considerando o atendimento das exigências de materiais didáticos, equipamentos, laboratórios e condições de deslocamento dos alunos e professores apenas quando o atendimento escolar não puder ser assegurado diretamente nas comunidades rurais (Resolução 1/2002 do CNE/CEB, art. 15, II).

\section{Trabalho docente e acompanhamento das Secretarias de Educação às escolas multisseriadas}

O desenvolvimento do processo ensino-aprendizagem nas escolas multisseriadas tem sido muito influenciado pelas particularidades que caracterizam o trabalho docente e o acompanhamento das Secretarias Estaduais e Municipais de Educação às escolas do campo, conforme indicaram os sujeitos entrevistados durante a pesquisa:

- Na escola multisseriada, normalmente é um professor só e ele tem que ser servente, fazer e servir a merenda, ser tudo. Além da dificuldade de atuar em várias séries ao mesmo tempo, existe a dificuldade extraclasse que é de: cuidar da escola, de tudo. Essa é a grande dificuldade que o professor enfrenta, porque ele não fica só cuidando do plano de aula. Ele pensa no todo da escola. Ele tem que resolver todos os problemas pendentes da classe na secretaria de educação. Eu acho que tudo isso prejudica o ensino. (Prof. R. V. A.)

- As dificuldades que envolvem os professores das escolas multisseriadas são muitas porque o quadro maior é de contratados e isso é muito influenciado por questões políticas. A cada ano troca, aqueles que estão lecionando saem, muda o quadro de professores e há uma ruptura no processo. (Técnica da Semed J. C. M.)

- A presença da Secretaria em nossa comunidade é ausente, pois durante eu morar nesse local, há mais de 30 anos eu desconheço a presença da Secretaria de Educação em nossa comunidade. (Mãe e integrante da comunidade A. M. N. S.)

- A Secretaria fornece o barco, óleo, alimentação e o motorista, mas ainda assim tenho grande dificuldade para fazer o assessoramento pedagógico por causa da distância. A escola mais próxima fica a oito horas de barco da cidade, temos que sair às $5 \mathrm{~h}$ da manhã e passamos 3,4 ou 5 dias para lá e nem conseguimos visitar todas as escolas. (Técnica da Semed I. C. S.)

- É um pouco difícil a relação com a Secretaria de Educação porque eles têm algumas restrições. Professor do interior fala com a Secretaria só tal dia, e isso fica meio difícil, para a gente ir daqui e chegar lá, porque perdemos aula. Nos sentimos em $2^{\circ}$ plano na hora de ser atendido; primeiro as escolas seriadas da cidade, depois as escolas do interior. Eu acho que a escola da cidade é a vitrine para a sociedade. A sociedade organizada está lá, então, eles procuram colocar o que há de melhor na vitrine, e depois vem o interior, pois aqui não tem ninguém vendo e não vai interessar politicamente para eles. (Prof. R. V.)

Identificamos por meio dos depoimentos explicitados que as condições adversas presentes no cotidiano das escolas 
multisseriadas impõem aos professores uma sobrecarga de trabalho, forçando-os a assumir um conjunto de outras funções para além da docência na escola. Entre as funções diagnosticadas na investigação encontram-se as de faxineiro, líder comunitário, diretor, secretário, merendeiro, agricultor, agente de saúde, parteiro, etc. Nessas escolas, o trabalho docente tem pouca autonomia em face das questões políticas que envolvem o poder local e interferem na dinâmica das secretarias de educação, submetendo os professores a uma grande rotatividade (mudança constante de escola) em função de sua instabilidade no emprego.

Além dessas particularidades, os professores, pais e integrantes das comunidades envolvidos com as escolas multisseriadas se ressentem do apoio que as Secretarias Estaduais e Municipais de Educação deveriam dispensar às escolas do campo e afirmam ser estas discriminadas em relação às escolas da cidade, que têm prioridade em relação ao acompanhamento pedagógico e formação dos docentes. No entendimento desses sujeitos, essa situação advém do descaso dessas instâncias governamentais para com as escolas multisseriadas. Por parte do pessoal que atua nas secretarias de educação, as justificativas em relação à falta de acompanhamento pedagógico advêm da falta de estrutura e pessoal suficiente.

Essas situações, em seu conjunto, têm motivado as entidades representativas do movimento social do campo a reivindicar a valorização e formação específica de educadoras e educadores por meio de uma política pública permanente que priorize a formação profissional e política de educadores e educadoras do próprio campo, gratuitamente; a formação no trabalho que tenha por base a realidade do campo e o projeto político-pedagógico da Educação do Campo; incentivos profissionais e concurso diferenciado para educadores e educadoras que trabalham nas escolas do campo; garantia do piso salarial profissional nacional e de plano de carreira; formas de organização do trabalho que qualifiquem a atuação dos profissionais da Educação do Campo... tendo a clareza da necessidade de regulamentar o regime de colaboração e cooperação entre as três esferas do Poder Público quanto à sua responsabilidade na implementação das políticas de Educação (II CNEC, 2004, p. 6).

\section{Planejamento do currículo e organização do trabalho pedagógico nas escolas multisseriadas}

No entendimento dos sujeitos do campo, o sucesso na aprendizagem dos estudantes nas escolas multisseriadas em muito se relaciona com a adequação do planejamento curricular e a organização do trabalho pedagógico, conforme indicam os depoimentos seguintes:

- O planejamento não está dando para fazer escrito no papel, porque é multisseriado e eu teria que realizar um para cada série, e isso leva muito tempo, e eu não estou tendo esse tempo. Então a gente trabalha baseado no livro didático. (Prof. D. C.)

- Faço o planejamento por série. Eu pego o livro didático e tem muita coisa nele que é baseado mais para os alunos da cidade. A gente muda muita coisa. (Prof ${ }^{\text {a }}$ E. S.)

- Eu trabalho só num período, de 7 às $11 \mathrm{~h}$, com seis séries. Eu organizo o trabalho na sala de aula assim: todo dia, eu levo os cadernos dos menores (jardim II e III) para casa. Lá eu passo as atividades para eles. Chegando aqui, eu dou o caderno para eles e depois vou passar as atividades para a $1^{\mathrm{a}}, 2^{\mathrm{a}}$, $3^{\mathrm{a}}$ e $4^{\mathrm{a}}$ série. Quando uma está terminando, eu mando aguardar um pouquinho, enquanto atendo a outra que já acabou. Eu procuro ao máximo me esforçar para cumprir as atividades, usando os três quadros, apesar de ser difícil cumprir os conteúdos, devido serem muitas séries. Eu sinto dificuldade para pôr em prática o planejamento. São seis turmas, o tempo que estou explicando para uma, as outras crianças já estão dizendo: "professora, já acabou minha atividade; a senhora ainda não vem explicar para mim?" A gente tem que ter aquele fôlego, para reparar todas as turmas. (Prof ${ }^{a}$ K. A. D.)

- Uma das maiores dificuldades no multisseriado é a leitura. Existem crianças na $2^{\mathrm{a}}, 3^{\mathrm{a}}$ e até $4^{\mathrm{a}}$ série que não sabem ler. Isso dificulta muito o trabalho, porque elas estão numa série, 
mas não acompanham aquele nível. (Profa. C. M. S.)

- A gente prefere reprovar porque vemos a necessidade do aluno obter a aprendizagem. A Secretaria cobra da gente passar o aluno, mas não podemos aprovar se não há aprendizagem. Isso acontece mais na $1^{\mathrm{a}}$ e $2^{\mathrm{a}}$ séries. (Prof. J. M.)

- Já reprovei muitas vezes, faz tempo, eu estudava junto com a $3^{\mathrm{a}}$ e $4^{\mathrm{a}}$ série e ficava ruim, a professora passava mais trabalhos para eles. Ela dava uma coisa para a gente e ficávamos esperando ela passar para os outros. Já desisti de estudar por causa do trabalho com meu pai, ele trabalha no mato e na serraria. (Aluno A. J. F.)

- A evasão e a repetência existem mais por causa das faltas. Tem o período de plantar na roça em que eles passam uma semana para plantar e faltam na escola. Também, tem muitos pais que não tem um lugar fixo, passam um mês aqui e vão para outro lugar trabalhar, vão e voltam, causando a repetência e a evasão. (Prof. A. L.)

Os depoimentos revelam que os professores enfrentam dificuldades em realizar o planejamento nas escolas multisseriadas, porque trabalham com muitas séries ao mesmo tempo, envolvendo estudantes de diversas faixas etárias, interesses e níveis de aprendizagem. A alternativa mais utilizada para solucionar o problema e viabilizar o planejamento numa situação dessa natureza tem sido seguir as indicações do livro didático, sem, contudo, atentar com clareza para as implicações curriculares resultantes dessa atitude, uma vez que esses materiais didáticos impõem a definição de um currículo deslocado da realidade e da cultura das populações do campo da região.

Identificamos ainda as angústias sentidas pelos professores ao organizar o trabalho pedagógico justamente porque assumem a visão da multissérie enquanto "junção de várias séries ao mesmo tempo e num mesmo espaço", passando a elaborar tantos planos de ensino e estratégias de avaliação da aprendizagem diferenciados quantas forem as séries presentes em sua turma. Como resultado, os professores se sentem ansiosos ao pretender realizar o trabalho da melhor forma possível e, ao mesmo tempo, perdidos, carecendo de apoio para organizar o tempo escolar, numa situação em que atua em várias séries concomitantemente. Eles também se sentem pressionados pelo fato de as secretarias de educação definirem encaminhamentos padronizados de horário do funcionamento das turmas, de planejamento e listagem de conteúdos, reagindo de forma a utilizar sua experiência docente acumulada e criatividade para organizar o trabalho pedagógico adotando medidas diferenciadas em face das especificidades das turmas.

No entanto, o acúmulo de funções e tarefas que assumem nas escolas multisseriadas dificulta aos professores realizar o atendimento adequado aos estudantes que não dominam a leitura e a escrita, implicando a elevação das taxas de reprovação e defasagem idade-série nas turmas. Por outro lado, essa situação se torna problemática, porque os professores são pressionados pelas secretarias de educação a aprovar o maior número de estudantes possível no final do ano letivo, como forma de relativizar os índices elevados de fracasso escolar.

Além de todos esses fatores, muitos estudantes ainda são obrigados a se ausentar ou abandonar a escola para realizar atividades produtivas ou acompanhar os pais em atividades de trabalho itinerantes, de pouca rentabilidade, prejudiciais à saúde e sem condições de segurança, em face das precárias condições de vida que enfrentam os sujeitos no campo, corroborando para dificultar ainda mais a organização do trabalho pedagógico nas escolas multisseriadas.

Apontando indicadores para referenciar políticas e práticas educacionais emancipatórias para o campo na Amazônia e no País.

Após a identificação das principais mazelas referentes à ação educativa que se desenvolve nas escolas multisseriadas, discutiremos indicadores que possam referenciar práticas e políticas educacionais emancipatórias para o campo na Amazônia e no País, apresentando um conjunto de reflexões que estimulem o debate sobre a realidade das escolas multisseriadas e seus desafios para garantir às populações do campo o direito à educação de qualidade na primeira etapa do ensino fundamental. 
1) As escolas multisseriadas devem sair do anonimato e ser incluídas na agenda das Secretarias Estaduais e Municipais de Educação, do Ministério da Educação, das universidades e centros de pesquisa e dos movimentos sociais do campo. Elas não podem continuar sendo tratadas como se não existissem, excluídas até das estatísticas do censo escolar oficial. Não há justificativa para tamanha desconsideração do poder público e da sociedade civil para com os graves problemas de infra-estrutura e de condições de trabalho e aprendizagem que enfrentam os professores e estudantes das escolas multisseriadas, que, em geral, se encontram abandonadas às situações contingentes próprias das comunidades em que se localizam; afinal, delas depende atualmente a iniciação escolar da maioria das crianças, adolescentes e jovens do campo.

2) O enfrentamento dos graves problemas que envolvem as escolas multisseriadas, para ser efetivo, deve considerar os desafios mais abrangentes que envolvem a realidade socioeconômica-políticaambiental-cultural e educacional do campo na sociedade brasileira contemporânea. Entre esses desafios, destacamos, por um lado, a degradação das condições de vida dos homens e das mulheres que vivem no campo, que resulta numa expansão acelerada da migração campo-cidade, e, por outro, o fortalecimento de uma concepção urbanocêntrica de mundo que dissemina um entendimento generalizado de que o espaço urbano é superior ao campo, de que a vida na cidade oferece o acesso a todos os bens e serviços públicos, de que a cidade é o lugar do desenvolvimento, da tecnologia e do futuro, enquanto o campo é entendido como o lugar do atraso, da ignorância, da pobreza e da falta de condições mínimas de sobrevivência.

3) As escolas multisseriadas têm constituído sua identidade referenciada na "precarização do modelo urbano seriado de ensino", e, para que elas ofereçam um processo educativo de qualidade, faz-se necessária a transgressão desse padrão de organização do ensino, que tem se constituído um empecilho em face da rigidez com que trata o tempo escolar, impondo a fragmentação em séries anuais e submetendo os estudantes a um processo contínuo de provas e testes como requisito para que sejam aprovados e possam progredir no interior do sistema educacional. Ao mesmo tempo, o modelo seriado se pauta por uma lógica "transmissiva", que organiza todos os tempos e espaços dos professores e dos alunos em torno dos "conteúdos" a serem transmitidos e aprendidos, transformando os conteúdos no eixo vertebrador da organização dos graus, séries, disciplinas, grades, avaliações, recuperações, aprovações ou reprovações (SEF/MEC, 1994). Miguel Arroyo (1999), analisando essa problemática, afirma que os índices alarmantes de fracasso escolar em muito se devem à escola seriada "peneiradora", seletiva e excludente, que é a própria negação da escola como direito de todos, universal.

4) As escolas multisseriadas têm assumido um currículo deslocado da cultura das populações do campo, situação que precisa ser superada caso se pretenda enfrentar o fracasso escolar e afirmar as identidades culturais das populações do campo. Reconhecemos que ainda predominam em nossos sistemas de ensino compreensões universalizantes de currículo, orientadas por perspectivas homogeneizadoras que sobre-valorizam concepções mercadológicas e urbanocêntricas de vida e desenvolvimento e desvalorizam as identidades culturais das populações que são do campo e nele vivem, interferindo em sua auto-estima. Não obstante, o enfrentamento dessa situação desastrosa no contexto da educação do campo pode ser alcançado através da construção coletiva de um currículo que valorize as diferentes experiências, saberes, valores e especificidades culturais das populações do campo da Amazônia. Sinalizamos, assim, a importância da 
concretização de um processo de educação dialógica que inter-relacione sujeitos, saberes e intencionalidades, superando a predominância de uma educação bancária de forte tradição disciplinar, pois entendemos que os saberes da experiência cotidiana no diálogo com os conhecimentos selecionados pela escola propiciam o avanço na construção e apropriação do conhecimento por parte dos educandos e dos educadores.

5) As escolas multisseriadas oportunizam às populações do campo o acesso à escolarização no lugar em que vivem, em sua própria comunidade, fator que poderia contribuir significativamente para a permanência dos sujeitos no campo e para a afirmação de suas identidades culturais, não fossem todas as mazelas que envolvem a dinâmica educativa efetivada nessas escolas, detalhadas anteriormente. Essa é uma questão importante a ser considerada, pois entre as reivindicações dos movimentos sociais populares do campo encontra-se a afirmação do direito inalienável que todos os sujeitos têm de serem educados no próprio lugar em que vivem e convivem com seu grupo social, o qual constitui pré-requisito fundamental para o fortalecimento dos laços de pertencimentos dos sujeitos e para a afirmação das identidades culturais das populações do campo. A escola localizada no próprio espaço em que vivem e convivem os sujeitos do campo pode constituir-se num centro de desenvolvimento cultural da comunidade, envolvendo a todos, sem exceção - crianças, adolescentes, jovens e adultos, estudantes, pais, lideranças e membros da comunidade -, nos processos de apropriação do conhecimento e de mobilização e participação coletiva na construção de uma sociedade inclusiva, democrática e plural.

6) As escolas multisseriadas são espaços marcados predominantemente pela heterogeneidade, ao reunir grupos com diferenças de série, de sexo, de idade, de interesses, de domínio de conhecimentos, de níveis de aproveitamento, etc. Essa heterogeneidade inerente ao processo educativo da multissérie, articulada a particularidades identitárias relacionadas a fatores geográficos, ambientais, produtivos, culturais, etc., são elementos imprescindíveis na composição das políticas e práticas educativas a serem elaboradas para a Região Norte e para o País. Essa prerrogativa referencia nossa intencionali-dade de pensar a educação do lugar dos sujeitos do campo, o que significa que, se temos por pretensão elaborar políticas e práticas educativas includentes para as escolas do campo, é fundamental reconhecer e legitimar as diferenças existentes entre os sujeitos, entre os ecossistemas e entre os processos culturais, produtivos e ambientais cultivados pelos seres humanos nos diversos espaços sociais em que se inserem. Não obstante, não podemos desconsiderar a visão dos sujeitos envolvidos com a multissérie, que consideram toda essa heterogeneidade mencionada como um fator que dificulta o trabalho pedagógico, fundamentalmente porque se tem generalizado na sociedade que as "classes homogêneas" são o parâmetro de melhor aproveitamento escolar e, conseqüentemente, de educação de qualidade. Contudo, os fundamentos teóricos que orientaram a realização da pesquisa apontaram justamente o contrário, indicando ser a heterogeneidade um elemento potencializador da aprendizagem e que poderia ser mais bem aproveitado na experiência educativa que se efetiva na multissérie, carecendo, no entanto, de muitos estudos e investigações sobre a organização do trabalho pedagógico, sobre o planejamento e a construção do currículo e de metodologias adequadas às peculiaridades de vida e de trabalho das populações do campo, o que de forma nenhuma significa a perpetuação da experiência precarizada de educação que se efetiva nas escolas multisseriadas tal qual identificamos nesse estudo. 


\section{Referências bibliográficas}

ARROYO, M. G.; FERNANDES, B. M. A educação básica e o movimento social do campo. Brasília: Articulação Nacional por uma Educação do Campo, 1999. (Coleção Por uma Educação do Campo, 2).

BRASIL. Ministério da Educação. Secretaria de Educação Continuada, Alfabetização e Diversidade. Elementos para um plano nacional de educação do campo: por uma política de educação do campo. Disponível: http://portal.mec.gov.br/secad/. Acesso em: 20 dez. 2005.

BRASIL. Ministério da Educação. Secretaria de Educação Fundamental. Escola plural: proposta político-pedagógica. Brasília: SEF, 1994.

CALDART, Roseli Salete. Pedagogia do Movimento Sem Terra: escola é mais do que escola. Petrópolis: Vozes. 2000.

CONSELHO NACIONAL DE EDUCAÇÃO. CEB. Diretrizes Operacionais para a Educação Básica nas Escolas do Campo. Resolução CNE/CEB N 1, de 3 de abril de 2002.

GEPERUAZ. Dados referentes à realidade das escolas multisseriadas no Estado do Pará. Disponível: http://www.ufpa.br/ce/geperuaz/. Acessado em: 23 set. 2004.

. Relatório conclusivo da pesquisa "Classes Multisseriadas: desafios da educação rural no Estado do Pará/Região Amazônica", apresentado ao CNPq. Belém-PA, 2004.

INSTITUTO NACIONAL DE ESTUDOS E PESQUISAS EDUCACIONAIS. Sinopse Estatística da Educação Básica: Censo Escolar 2002. Brasília: Inep, 2002.

. Sinopse Estatística da Educação Básica: Censo Escolar 2003. Brasília: Inep, 2002.

II CNEC. Por uma Política Pública de Educação do Campo. Texto Base da II Conferência Nacional por uma Educação do Campo. Luziânia, 2004.

RAMOS, Marise Nogueira et al. (Coord.). Referências para uma política nacional de educação do campo: caderno de subsídio. Brasília: Secretaria de Educação Média e Tecnológica. Grupo Permanente de Trabalho de Educação do Campo. 2004.

Salomão Antônio Mufarrej Hage, doutor em Educação pela Pontifícia Universidade Católica de São Paulo (PUC-SP), é professor adjunto do Centro de Educação da Universidade Federal do Pará (UFPA).

salomao@uol.com.br

Recebido em 2 de maio de 2006.

Aprovado em 11 de setembro de 2006. 